\title{
Propriedade intelectual e saúde pública: a cópia de medicamentos contra HIV/Aids re- alizada por laboratórios farmacêuticos brasi- leiros públicos e privados
}

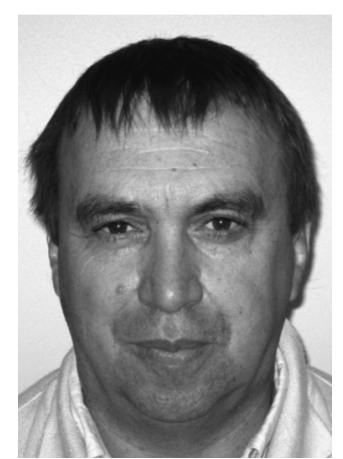

\section{Maurice Cassier}

Centre National de la Recherche Scientifique, Paris, França

cassier@pop.vjf.cnrs.fr

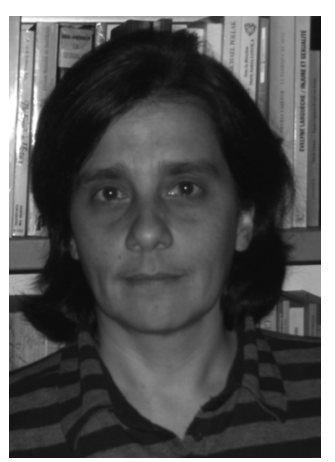

Marilena

Correa

Universidade Estadual do Rio de Janeiro - Uerj, Rio de Janeiro, Brasil mcorrea@ism.com.br

\section{Resumo}

A experiência dos laboratórios brasileiros públicos e privados em copiar ARVs (anti-retrovirais), desde 1993, constitui um processo de aprendizado tecnológico que, em alguns casos, produziu inovações. Reproduzir medicamentos e sintetizar seus princípios ativos envolve a combinação de informações disponíveis em patentes e a redescoberta parcial de um certo know-how por meio de manipulações em laboratórios. Os químicos devem reconstituir os diversos "pulos-do-gato" existentes nas patentes e, ao fazê-lo, freqüentemente melhoram processos e fórmulas publicados. Os laboratórios de genéricos também estão aptos a utilizar essa base de conhecimento para criar novas fórmulas, combinações de moléculas existentes ou para descobrir novas moléculas. Desde 2000, os cinco laboratórios estudados registraram dez patentes de ARVs. Aos poucos, descobrimos esse processo de aprendizado tecnológico, por meio de entrevistas realizadas com químicos em laboratórios de genéricos, usando métodos da sociologia da ciência.

\section{Palavras-chave}

Patentes, engenharia reversa, aprendizado tecnológico, inovações farmacêuticas

\section{Introdução}

Em 2 de junho de 2005, a Comissão de Constituição e Justiça e de Cidadania da Câmara dos Deputados brasileira aprovou, por unanimidade, um projeto de lei para colocar os medicamentos contra HIV/Aids fora da esfera das matérias patenteáveis ${ }^{1}$. Membro do parlamento, Roberto Gouveia, justificou essa alteração na lei de propriedade intelectual brasileira de 1996 nos seguintes termos: "As patentes que estiverem em conflito com os interesses da saúde pública devem ser suspensas.” Três semanas depois, no dia 23 de junho, o ministro da Saúde anunciou uma licença compulsória autorizando o laboratório estatal Far-Manguinhos, da Fundação Oswaldo Cruz, no Rio de Janeiro, a iniciar a produção de uma combinação de duas moléculas anti-retrovirais sem autorização do dono da patente. Essas medidas de exclusão da patenteabilidade ou a suspensão de patentes concernentes especificamente aos medicamentos contra a 
Aids foram conseqüência do fracasso nas negociações do Ministério da Saúde com três laboratórios farmacêuticos internacionais (Abbott, Merck e Gilead). O Ministério tinha esperança de obter reduções dos preços de quatro anti-retrovirais patenteados, responsáveis por 4/5 dos gastos do programa brasileiro contra a Aids. Os laboratórios internacionais recusaram-se também a conceder licenças voluntárias para os laboratórios brasileiros que as tinham solicitado, especialmente o laboratório do governo federal Far-Manguinhos. Considerou-se que a concessão de uma licença compulsória e a conseqüente produção local desses medicamentos pelos laboratórios brasileiros tinha uma dupla vantagem - referente à saúde pública e à indústria - para o Brasil. Em relação à saúde pública, a expectativa era de que versões de genéricos custassem a metade do preço dos medicamentos de propriedade patenteada. Em relação à indústria, os laboratórios brasileiros públicos e privados poderiam, assim, usar sua capacidade de produção e pesquisa, desenvolvida desde meados da década de 1990, no campo dos ARVs para lutar contra a Aids. No entanto, poucas semanas depois, o Ministério da Saúde brasileiro desistiu de usar a licença compulsória e anunciou que chegara a um acordo satisfatório com o Abbott sobre o preço do medicamento em questão, o Kaletra. Líderes do programa contra a Aids, assim como ONGs, condenaram essa decisão, pois acreditavam que comprometeria a continuidade da produção local de genéricos e a viabilidade do programa de livre distribuição de triterapias no Brasil ${ }^{2}$. Esses conflitos sobre a propriedade intelectual dos anti-retrovirais são recorrentes no Brasil desde 1996, quando o país iniciou um programa de distribuição universal de medicamentos contra HIV/Aids e de produção local de genéricos ${ }^{3}$.

Neste texto, consideramos as condições de surgimento dessa indústria de genéricos na intersecção entre a política de saúde pública, os direitos de propriedade intelectual e a política industrial nas áreas química e farmacêutica. A primeira seção mostra como a produção local de genéricos corresponde à política de acesso universal aos medicamentos contra HIV/Aids implementada pelo Ministério da Saúde desde 1996. A segunda seção apresenta a situação muito particular relativa à propriedade intelectual no Brasil, que prevaleceu até 1996, ou seja, a situação não-patenteável de medicamentos, que permitia a cópia lícita de ARVs. Na terceira seção, examinamos a prática de copiar medicamentos nos laboratórios farmacêuticos brasileiros e o aprendizado tecnológico que a acompanha. A quarta seção estuda os processos de inovação possíveis de serem gerados pelo ato de copiar: seja o maior desenvolvimento dos processos de produção farmacêutica ou das fórmulas dos medicamentos copiados, seja o início de novos projetos de pesquisa sobre novas gerações de ARVs que se beneficiam da base de conhecimentos adquiridos durante a fase de copiar. A quinta seção considera a situação criada pela nova lei de patentes de 1996 que, por um lado, proíbe a cópia de novas gerações de anti-retrovirais e, por outro, possibilita que laboratórios brasileiros protejam suas descobertas de novas moléculas e de novas fórmulas de medicamentos.
Finalmente, a conclusão retoma a situação excepcional relativa aos medicamentos contra HIV/Aids no Brasil, que, originalmente, podiam ser livremente copiados e que, a partir de 1997, passaram então a ser patenteáveis. Atualmente, esses medicamentos são objeto de controvérsia sobre a concessão de licenças compulsórias e sobre sua possível nova exclusão da lei de patentes ${ }^{4}$. Demonstramos, também, que as patentes desempenham um duplo papel nessa história: o de instrumentos de reserva de invenções e o de veículos de transferência de tecnologia. Além disso, essa experiência fornece material interessante para reflexão sobre o papel das assimetrias da propriedade intelectual, justificadas tanto pelas políticas de saúde pública como pelo desenvolvimento industrial ${ }^{5}$.

\section{Política de saúde pública e produção local de medicamentos genéricos}

$\mathrm{Na}$ experiência brasileira de combate à Aids, com sua abordagem baseada no acesso universal ao tratamento e na cópia de anti-retrovirais realizada por laboratórios famacêuticos brasileiros, a característica mais singular é o emaranhado entre as políticas de saúde pública e as de medicamentos industriais. Esta mistura distingue o Brasil da Índia, onde a indústria de genéricos desenvolveu-se na estrutura estrita dos incentivos de mercado ${ }^{6}$. Em novembro de 1996, o presidente do Brasil sancionou uma lei instituindo "a livre distribuição de medicamentos para os portadores de HIV/Aids" . O decreto presidencial, que atribuiu um status excepcional à epidemia de Aids, colocou os medicamentos para combatê-la fora da esfera do mercado, uma vez que foram comprados e distribuídos livremente pelo Ministério da Saúde por intermédio do sistema de saúde pública. O decreto estipulou também a criação de uma comissão para definir a lista de medicamentos que podiam ser classificados como triterapias. Essa lista deveria ser revista anualmente de modo a "considerar o avanço do conhecimento científico e os novos medicamentos comercializados". O fato mais original é que o governo brasileiro não ficou apenas nesse papel de distribuir mercadorias consideradas essenciais. Tornou-se também um "empreendedor da saúde" através do trabalho dos laboratórios farmacêuticos estatais, que deram início à produção local de anti-retrovirais. Esses laboratórios públicos constituem uma instituição altamente original no Brasil. São de propriedade do Ministério da Saúde, como é o caso do Instituto de Tecnologia em Fármacos da Fundação Oswaldo Cruz no Rio de Janeiro, conhecido como Far-Manguinhos, ou estaduais ${ }^{8}$. Em 1996, os diretores dos laboratórios estatais e o Ministério da Saúde fizeram um acordo para iniciar um programa para copiar ARVs, precisamente com o objetivo de reduzir o preço desses medicamentos, que absorviam uma enorme proporção do orçamento do Ministério. O desenvolvimento da produção de genéricos ou similares no Brasil objetivava reduzir o número de moléculas patenteadas compradas de laboratórios internacionais líderes no mercado e forçar a queda de preços? O programa contra a Aids teve o efeito de revitalizar a 
produção em laboratórios farmacêuticos públicos. O laboratório estatal Far-Manguinhos, amplamente inativo no início da década de 1990, multiplicou sua produção por sete e sua renda por 20 no período de 1995 a 2002. Desenvolveu uma linha de produção especial para os ARVs, certificada pela agência brasileira de medicamentos, Anvisa (Agência Nacional de Vigilância Sanitária), em setembro de 2002. O Far-Manguinhos reinvestiu seus lucros em pesquisa, contratou químicos recrutados na indústria e na academia, e comprou equipamentos de pesquisa e outros. Hoje, esse laboratório é uma plataforma técnica que serve como referência para a indústria farmacêutica brasileira.

A partir de 1993, vários laboratórios particulares também começaram a copiar e produzir ARVs para lutar contra o HIV/Aids. Naquele ano, um pequeno laboratório químico-farmacêutico, pequena empresa recém-criada por químicos da Universidade Federal do Rio de Janeiro, começou a copiar o AZT. Dois outros laboratórios, ligados à Universidade de Campinas e à Universidade de São Paulo, iniciaram seu programa para copiar o AZT e inibidores de protéases em 1994 e 1996. O último laboratório particular a entrar no campo dos ARVs o fez, em 2000, a pedido do Far-Manguinhos, que precisava de matéria-prima para sua produção de ARVs. Essa empresa de genéricos, localizada perto do Rio de Janeiro, criada na década de 1980 por químicos do laboratório federal, trabalha em intensa cooperação com o Far-Manguinhos. As duas organizações, uma pública e a outra privada, são ligadas por um contrato de cooperação tecnológica. Para os laboratórios do setor privado que trabalham nessa área, as compras do Ministério da Saúde significaram uma garantia de vendas, pelo menos até o sistema de compras públicas, baseado no menor preço, beneficiar laboratórios indianos e chineses em detrimento dos produtores nacionais. Às vezes, o Ministério da Saúde solicita diretamente aos laboratórios particulares que desenvolvam tecnologias de síntese de ARVs, principalmente quando o governo brasileiro quer pressionar os laboratórios internacionais a reduzirem seus preços. O governo pode depender também dos produtores particulares de genéricos para repor os produtos que um laboratório internacional retira do Brasil: "O Ganciclovir, quando a Roche parou de fornecer para o governo brasileiro, o governo nos perguntou se seríamos capazes de desenvolver esse medicamento no Brasil. Respondemos: Desenvolveremos a síntese, e ajudamos o governo a desenvolver a metodologia de liofilização." (Diretor do Laboratório)

Os laboratórios farmacêuticos do governo têm uma capacidade industrial limitada na produção de medicamentos. Eles são capazes de levar a cabo somente a fase de produção final, ou seja, a fórmula e a produção do medicamento, mas não a síntese de seus princípios ativos. Estes eles compram dos laboratórios do setor privado brasileiros, indianos e chineses. Assim, há uma complementariedade entre laboratórios públicos, especializados em fórmulas, e os laboratórios comerciais, que fornecem a matéria-prima. No caso de algumas moléculas antiretrovirais, laboratórios públicos e privados cooperam, trocam conhecimentos e transferência de tecnologia ${ }^{10}$. Em alguns casos, laboratórios dos dois setores competem quando formulam os mesmos medicamentos.

\section{O status não-patenteável de medica- mentos no Brasil de 1945 a 1996: um regime de cópia lícita}

O engajamento de laboratórios brasileiros públicos e privados na cópia de medicamentos contra HIV/Aids foi possível devido ao status particular dos medicamentos como "bens públicos" no Brasil de 1945 a 1996. Em 1945, o presidente Getúlio Vargas decretou que os produtos farmacêuticos não seriam patenteáveis com o duplo objetivo de desenvolvimento da saúde pública e da indústria. A idéia era estimular a produção de medicamentos para as doenças mais sérias no país e incentivar a criação de uma indústria farmacêutica local para fabricar produtos que substituíssem os importados. Essa exclusão foi reforçada em 1971 durante o governo militar. A nova lei de propriedade industrial excluiu do patenteamento tanto os processos de produção como os produtos farmacêuticos, com o objetivo de promover a transferência de tecnologia e fortalecer um setor essencial para a população local ${ }^{11}$. A cópia de medicamentos patenteados no exterior era, portanto, perfeitamente legal.

A política de copiar ARVs para HIV/Aids estava ligada aos experimentos em engenharia reversa nos anos 1970 e 1980. Durante a década de 1980, o Ministério da Saúde criou um sistema de incentivos tributários e vantagens financeiras para estimular a cópia de medicamentos e a produção de matérias-primas pela indústria farmacêutica e química. Os laboratórios trabalhavam correntemente no campo da Aids subsidiados por essa ajuda. O diretor técnico de um laboratório, criado em 1989, que produzia genéricos, explicou: "Nossos primeiros projetos da empresa foram financiados pelos projetos do Ministério da Saúde."

Essa situação legal favorável à cópia de invenções do exterior e a criação de uma indústria farmacêutica para substituir os medicamentos importados durou até 1996. Paradoxalmente, o Brasil alterou o status legal dos medicamentos em fevereiro de 1996, exatamente poucos meses antes da lei de livre acesso universal aos medicamentos contra HIV/Aids ser sancionada. Conseqüentemente, a produção legal de anti-retrovirais diz respeito somente à primeira geração de medicamentos, patenteados antes de 1996. A segunda geração de ARVs, protegidos por patentes, pode ser copiada somente por meio de uma licença compulsória.

\section{Cópias e aprendizado tecnológico}

A prática de copiar medicamentos, realizada por laboratórios brasileiros e indianos produtores de genéri$\cos ^{12}$, foi assunto de intensa controvérsia internacional. O Brasil foi acusado de "pirataria", mesmo quando copiar era legal naquele país, uma vez que reproduzia medicamentos sem pagar os custos de R\&D (sigla de Research and Development, ou seja, Pesquisa e Desenvolvimento) 
envolvidos em sua criação. A engenharia reversa também foi criticada como uma atividade redundante e fútil por reproduzir o que já foi inventado em outro lugar. Em novembro de 2002, a empresa GlaxoSmithKline resumiu copiar como um desperdício de recursos: "Os engenheiros que continuam na indústria farmacêutica na Índia gastaram seu tempo, pelo menos até recentemente, com a engenharia reversa para escapar das patentes de 'processos' existentes (isto é, reiventando a roda) mais do que com a inovação ... A história da Índia demonstra como um sistema de IP fraco pode, na melhor das hipóteses, levar à dissipação de esforço em R\&D na reengenharia...". ${ }^{13}$

Nossa pesquisa com químicos diretamente envolvidos nos projetos de cópia de ARVs em laboratórios públicos e privados brasileiros e com pessoas responsáveis pela propriedade intelectual e a transferência de tecnologia $^{14}$ mostra, ao contrário, um processo de aprendizado tecnológico ou o fenômeno learning-by-doing (aprenderfazendo) que resulta de copiar. A prática de copiar ARVs envolve a criação e a aquisição de conhecimento por químicos brasileiros e resulta no desenvolvimento e aperfeiçoamento da capacidade de R\&D desses laboratórios. Em determinados casos, essa nova base de conhecimento é usada para iniciar projetos de pesquisa sobre novas gerações de ARVs. Esse resultado inestimável para as políticas industriais farmacêuticas foi obtido por meio da metodologia da sociologia da ciência e da inovação que reconstrói as práticas de produção e circulação de conhecimento em laboratórios ${ }^{15}$.

Consideremos o trabalho de químicos que começam a copiar um ARV. O processo se inicia com uma pesquisa bibliográfica, primeiro sobre patentes internacionais, e, em seguida, sobre artigos científicos ou artigos publicados em jornais profissionais. Nesse período, os pesquisadores exploram o valor de uso documentado de patentes, que varia de acordo com a molécula. $\mathrm{O}$ engajamento do laboratório federal Far-Manguinhos na produção de ARVs, por exemplo, começou com análises detalhadas das patentes relevantes. Esta pesquisa, conduzida por um químico experiente, revelou problemas em sínteses altamente específicas, assim como gargalos para a aquisição de determinados reagentes. Em um laboratório privado, um engenheiro químico dedicou-se inteiramente a ler e sintetizar patentes, assim como a identificar os passos que dificultariam sua reprodução. Ler patentes envolve um processo de interpretação e transposição. Portanto, é necessário adaptar o processo descrito na patente às condições de produção que não são estritamente equivalentes às descritas na invenção. As informações contidas na patente são fundamentalmente incompletas devido a restrições feitas pelo proprietário e, mais comumente, à ausência do know-how requerido para aplicar a tecnologia descrita. Portanto, os químicos que trabalham em laboratórios de genéricos, que não têm o know-how do proprietário da patente, devem se responsabilizar pela reconstituição paciente da tecnologia. Para isso, utilizam informações encontradas em publicações, conhecimentos obtidos com outros produtores de genéricos (os químicos do Far-Manguinhos visitaram, várias vezes, as fábricas de seus fornecedores na Índia), e o know-how de químicos da universidade que lhes dão assessoria. Basicamente, eles têm de completar a patente por meio de pesquisa em laboratório para reconstituir alguns processos e analisar os medicamentos e a matéria-prima obtidos comercialmente. Aos poucos, os produtos têm como ser caracterizados e os processos sintéticos reproduzidos. A dificuldade dessa reconstituição, em meio a patentes, artigos científicos e engenharia reversa, varia conforme a complexidade das moléculas e o valor de uso das patentes documentado. Um fabricante de genéricos, do setor privado, levou dois anos para reproduzir a síntese do Ritonavir, um inibidor de protease. Foi preciso um ano para consegui-la na escala de laboratório e outro para uma escala maior. No processo, o laboratório naturalmente aprendeu muito sobre as mesmas gerações de moléculas. O gerente de R\&D explicou: "No caso do Ritonavir, levamos dois anos para desenvolver a síntese; para o Lopinavir, seis meses, porque o Lopinavir e o Ritonavir têm estruturas, em parte, similares; tipos semelhantes de química e de know-how; hoje, é mais fácil desenvolver novas sínteses."

Produtores de genéricos tiveram de reconstituir também as referências ou os padrões das moléculas que copiaram. Uma vez que essas moléculas tinham sido patenteadas, suas referências químicas não eram divulgadas nas farmacopéias internacionais. Por exemplo, o laboratório Far-Manguinhos produziu referências dessas moléculas para seu próprio uso - controle de qualidade na fábrica - e para a farmacopéia brasileira. O serviço de qualidade de um produtor de genéricos do setor privado formula seus próprios métodos analíticos para controlar a produção e obter aprovação da Anvisa, a agência nacional de medicamentos. Assim, copiar produz relatórios, bancos de dados, métodos de testes e documentação abundante para uso público e interno.

A produção de medicamentos genéricos contra a Aids estimulou a criação de laboratórios públicos e particulares e o aumento da capacidade de R\&D de ambos. Consideremos o exemplo de Far-Manguinhos, que recrutou químicos na indústria e em universidades e adquiriu uma grande quantidade de equipamentos de pesquisa, financiados pelos lucros das vendas de ARVs. O resultado é uma plataforma técnica que serve como referência para a indústria farmacêutica brasileira. Uma vez que esse laboratório havia comprado matérias-primas para seus medicamentos de laboratórios comerciais indianos, chineses e brasileiros, ele primeiro se equipou com um grande departamento analítico para realizar testes de caracterização nas moléculas. Esses testes foram, então, usualmente utilizados para controlar a qualidade da matéria-prima adquirida. Embora não estivesse equipado para fazer sínteses em escala industrial, o Far-Manguinhos criou um laboratório para sínteses em que reproduziu passos de processos de sintetização com o objetivo de caracterizar moléculas ou desenvolver procedimentos de sínteses a serem transferidos para a indústria. Finalmente, o laboratório público criou uma equipe para produzir medicamentos a serem transferidos para outros laboratórios públicos brasileiros. Em poucos anos, entre 1996 e 2002, o Far-Manguinhos criou um laboratório de R\&D para análises, sínteses e fórmulas, 
para o qual foram cerca de 30\% do staff do laboratório (215 pesquisadores de um total de 739 funcionários).

O programa de cópias de ARVs foi acompanhado da troca de conhecimentos e até mesmo de contratos de transferência de tecnologia entre laboratórios dos setores público e privado. Consideremos os dois exemplos que se seguem. No primeiro caso, o laboratório estatal realizou um estudo bibliográfico e desenvolveu a síntese completa de uma molécula que, em seguida, foi transferida para um laboratório industrial que se encarregou de aumentar a escala e a produção. No segundo, os dois laboratórios, o estatal e o industrial, fizeram acordos relativos a várias operações: o laboratório federal compraria matéria-prima do laboratório industrial, que lhe transferiria a tecnologia de produção do medicamento por ele detida. Os dois parceiros fizeram também um acordo de cooperação para um projeto de $R \& D$ sobre uma nova geração de antiprotéases identificadas pela Universidade Federal do Rio de Janeiro.

Assim, copiar leva à produção local de conhecimentos gerados pelo estudo de patentes e por manipulações de laboratórios. As patentes constituem um importante veículo de transferência de tecnologia, mesmo que sejam fundamentalmente incompletas. $\mathrm{O}$ conhecimento é comercializado entre produtores de genéricos que se especializam em diferentes fases da produção de medicamentos ou eles se tornam parceiros. Esse conhecimento criado pelas cópias provavelmente deve ser transferido para outros laboratórios. O laboratório estatal Far-Manguinhos transfere suas tecnologias para outros laboratórios brasileiros e o diretor ofereceu a tecnologia obtida pelos químicos brasileiros para laboratórios na África Oriental e Austral.

\section{Cópias e inovações farmacêuticas}

Observamos um certo grau de continuidade entre cópias farmacêuticas e inovação. Nos laboratórios estudados, copiar leva à inovação de várias maneiras. A primeira é a chamada inovação incremental, que deriva diretamente da atividade de copiar: produtores de genéricos melhoram as rotas de síntese ou fórmulas dos medicamentos que copiam. Essas modificações podem levar a patentes relacionadas a aperfeiçoamentos (fórmulas) ou são mantidas em segredo (novas rotas de síntese). A segunda é uma inovação mais radical, que pode levar ao desenvolvimento de novos medicamentos, seja por meio da combinação de várias moléculas existentes, seja por descobertas de novas propriedades nas moléculas polimorfas da molécula copiada, ou da identificação de novas famílias de medicamentos anti-retrovirais. Por exemplo, o laboratório de Far-Manguinhos analisa o polimorfismo de medicamentos anti-retrovirais existentes para descobrir novas propriedades terapêuticas. Está envolvido também nos projetos de pesquisa sobre novas família de medicamentos anti-retrovirais derivadas da pesquisa iniciada no próprio laboratório ou em laboratórios acadêmicos. No último caso, uma patente de um novo inibidor de protéase foi depositado juntamente com a Universidade Federal do Rio de Janeiro. Esses projetos de pesquisa de novas moléculas, que não dependem mais da cópia de invenções estrangeiras, beneficiam-se desse aprendizado tecnológico dos laboratórios durante a fase de imitação. A reprodução de moléculas existentes tem sido acompanhada da criação de equipes de R\&D e da aquisição de conhecimentos aprofundados sobre moléculas anti-retrovirais, que podem ser usados em novos projetos de pesquisa. Acompanhamos essa dinâmica em um dos laboratórios de medicamentos genéricos industriais que estudamos, que começou copiando ARVs antes de desenvolver suas próprias moléculas em parceria com a Universidade de São Paulo.

Essas novas moléculas descobertas por laboratórios de universidades ou as novas fórmulas inventadas por produtores de medicamentos são patenteadas. Por exemplo, uma nova família de inibidores de protéase, descoberta por um químico de uma universidade e desenvolvida pelo laboratório Far-Manguinhos, foi patenteada pela Universidade Federal do Rio e pelo laboratório do Ministério da Saúde. A patente abrange Europa, Estados Unidos, Japão, Chile, Índia e África do Sul. Essa patente deve possibilitar que a universidade e o laboratório estatal controlem a difusão e a industrialização do invento. Laboratórios privados de genéricos registraram patentes de novas fórmulas, dos processos de sua preparação - por exemplo, inibidores de protéase - e de novas moléculas por eles identificadas. Novas rotas de síntese baseadas no know-how muito específico de engenheiros químicos, que representam uma fonte de ganhos de produtividade para produtores de genéricos, são geralmente mantidas em segredo.

Os aperfeiçoamentos tecnológicos ou novos modelos descobertos pelos produtores de genéricos brasileiros beneficiam-se da nova lei de propriedade intelectual no que diz respeito a que produtos e processos farmacêuticos podem ser patenteados. O laboratório federal Far-Manguinhos pretende usar suas patentes para controlar e regular o mercado de medicamentos. Na maioria dos casos, deixará que outros laboratórios ou empresas industrializem novos medicamentos e produzam matérias-primas, e utilizará suas patentes para transferir suas tecnologias para laboratórios brasileiros. De maneira mais geral, com ou sem patentes, Far-Manguinhos tem uma política sistemática de transferência de tecnologia para a indústria privada. Processos desenvolvidos em escala de laboratório - correspondente a um quilograma - são enviados simultaneamente para as empresas interessadas. Um químico do laboratório federal comentou: “Tínhamos três moléculas para as quais foram desenvolvidas reações em escala de laboratório; depois, elas foram transferidas para empresas clientes que queriam a tecnologia."

Universidades brasileiras também têm políticas de propriedade intelectual e, em alguns casos, uma pessoa específica fica responsável pela monitoração do registro de patentes e transferências de tecnologia ${ }^{16}$. Por exemplo, uma equipe de químicos da Universidade Federal do Rio de Janeiro patenteou várias novas moléculas como parte de uma estratégia para valorizar a pesquisa acadêmica e para transferir e controlar tecnologia. Existe uma rede de universidades brasileiras para estimular a propriedade intelectual e difundir instrumentos de transferências. Ao 
longo de sua atividade de copiar genéricos, produtores brasileiros de medicamentos genéricos usam patentes relacionadas a aperfeiçoamentos ou patentes de novas moléculas quando desejam desenvolver pesquisa farmacêutica com o objetivo de inventar novos produtos, geralmente em cooperação com laboratórios de universidades. No entanto, esses projetos de inovação baseada em novas moléculas ainda estão em um estágio muito inicial.

\section{Conflito entre o Ministério da Saúde brasileiro e os laboratórios internacio- nais: negociações dos preços e licen- ças compulsórias}

Embora a lei de patentes de 1996 sirva para proteger invenções de novas moléculas, exclui a possibilidade de copiar novas gerações de anti-retrovirais. Acredita-se que a produção de genéricos brasileiros contra a Aids diminuirá logo que os "coquetéis" adotados pelo Ministério da Saúde para suas triterapias incluírem as novas moléculas patenteadas. À medida que o Ministério optar por tratamentos que incluam essas novas moléculas patenteadas, gradualmente o mercado de medicamentos copiados diminuirá.

Em três ocasiões - agosto de 2001, setembro de 2003 e junho de 2005 - durante as negociações de preço com laboratórios internacionais, o governo brasileiro ameaçou usar uma licença compulsória para os ARVs patenteados. Os quatro ARVs de segunda geração comprados pelo Ministério da Saúde correspondiam a 80\% do orçamento do programa contra Aids, e os detentores de patentes recusaram-se a conceder as reduções de preços demandadas. Em junho de 2005, por exemplo, o Ministério da Saúde ameaçou ter o genérico do Kaletra, do laboratório Abbott, produzido pelo Far-Manguinhos, por quase metade do preço do medicamento que detém a marca ${ }^{17}$. A ameaça era plausível, uma vez que o laboratório estatal tinha ampla experiência na área dos anti-retrovirais e havia preparado a engenharia reversa do medicamento por solicitação do Ministério da Saúde. Uma vez que a preparação de uma licença compulsória exige a capacidade de produzir a molécula licenciada, o Ministério da Saúde requer diretamente a laboratórios públicos e privados que preparem a síntese de moléculas específicas. Esse trabalho preparatório de aquisição de conhecimento é crucial para o governo brasileiro, pois ele só pode decidir usar uma licença compulsória se os químicos do país forem capazes de produzir a molécula genérica por um preço satisfatório. Finalmente, em julho de 2005, o Ministério da Saúde anunciou um acordo em relação aos preços do Kaletra e desistiu da opção por uma licença compulsória e da produção de versões genéricas. Um dos líderes do programa contra a Aids do Ministério criticou essa decisão, que reduziu a esfera da produção local de genéricos: "ARVs copiados aqui são cada vez menos usados com o aparecimento de novos tratamentos." $\mathrm{Na}$ verdade, apesar de várias ameaças, o Brasil nunca efetivou esse tipo de licença compulsória.

Paralela a essa batalha relacionada às licenças compulsórias, membros do parlamento, apoiados por ONGs, propuseram uma outra solução mais radical: a emenda à lei de 1996 sobre propriedade intelectual, de modo que os ARVs fossem excluídos da patenteabilidade. Em 2 de junho de 2005, a Comissão de Constituição e Justiça e de Cidadania da Câmara dos Deputados brasileira aprovou, por unanimidade, um projeto de lei para colocar os medicamentos contra HIV/Aids fora da esfera das matérias patenteáveis ${ }^{18}$. Esse artigo, que ratifica $o$ status excepcional da Aids, foi explicitamente destinado a garantir a viabilidade do programa do Ministério da Saúde contra a Aids. O objetivo é não só reduzir os preços dos ARVs, mas também assegurar que sua produção local possa continuar. Essa exclusão de ARVs das patentes poderia, no entanto, impedir o patenteamento de novas moléculas que viriam a ser descobertas pelos pesquisadores brasileiros dos setores público e privado.

\section{Conclusões}

A experiência brasileira de copiar medicamentos contra HIV/Aids ilustra uma série de questões. Primeiro, enfatiza o status excepcional de medicamentos em relação à propriedade intelectual. Considerados bens públicos, os medicamentos podiam ser copiados livremente no Brasil até 1996. Embora tenham caído novamente sob a lei de patentes naquele ano, permaneceram "bens essenciais" em relação às normas da política de saúde pública. Em 1996, poucos meses depois da nova lei de propriedade intelectual ter sido sancionada, um decreto presidencial proclamou o acesso livre universal aos medicamentos para portadores de HIV/Aids. Para pôr em prática essa política, o governo mobilizou laboratórios farmacêuticos públicos para produzirem medicamentos genéricos. Esses objetivos de saúde pública entraram em conflito com o status patenteável de novas gerações de medicamentos anti-retrovirais quando os preços das novas moléculas pesaram muito no orçamento do Ministério da Saúde. Por isso os inúmeros conflitos com os laboratórios particulares e controvérsias sobre licenças compulsórias desde 2001. O limite aos direitos das patentes encontrase inscrito na nova lei de patentes e pode ser aplicado se o produto patenteado não for produzido localmente durante três anos. Em 1999, um decreto presidencial fortaleceu as possibilidades de licenças compulsórias "de interesse público" principalmente relacionadas à saúde pública. Em setembro de 2003, um novo decreto presidencial especificou as condições para a aplicação de uma licença compulsória por motivos emergenciais de interesse público nacional. A propriedade intelectual de ARVs teve de se adaptar às normas da saúde pública. Finalmente, os incentivos públicos do Ministério da Saúde relativos à Aids foram decisivos para revitalizar a produção de genéricos no Brasil.

Em segundo lugar, essa experiência revela também as possibilidades abertas à saúde pública, à transferência e ao aprendizado tecnológico pela assimetria nos direitos de propriedade intelectual de diferentes países ${ }^{19}$. Nesse sentido, licenças compulsórias podem ser consideradas do ponto de vista não só das políticas de saúde pública, mas também da transferência de tecnologia. O acordo da OMC, em 30 de agosto de 2003, sobre a aplicação da 
Declaração de Doha, contém um artigo que "reconhece" e estimula a "transferência de tecnologia" entre os países importadores e exportadores de medicamentos genéri$\cos ^{20}$. O decreto do presidente do Brasil, de setembro de 2003, relativo às licenças compulsórias, objetivou compelir os detentores de patentes a transferirem seu know-how. A própria preparação de licenças compulsórias constitui uma fase da aquisição de conhecimentos e de aprendizado tecnológico, por meio da análise de documentos de patentes, engenharia reversa em laboratórios, trocas entre laboratórios públicos e privados, e visitas de químicos a produtores de genéricos indianos e chineses ${ }^{21}$.

Em terceiro, a complexidade de patentes é revelada. Patentes são instrumentos para proteger invenções e proibir a cópia em detrimento de produtores de genéricos. São também veículos de transferência de tecnologia quando copiar é declarado legal, seja porque o medicamento é excluído da patenteabilidade ou porque as patentes em questão estão sujeitas a uma licença compulsória. Por último, patentes constituem uma faca de dois gumes para as empresas farmacêuticas no Brasil. Por um lado, se ratificada, a reforma da lei de propriedade intelectual aprovada pela Câmara dos Deputados em junho de 2005 excluirá os ARVs das patentes e estimulará a ampliação do mercado de cópias. Por outro, impedirá laboratórios públicos e privados de patentear aperfeiçoamentos ou novas moléculas. Um produtor de genéricos que produzir os princípios ativos de ARVs existentes e descobrir novos ARVs enfrentará esse dilema.

Finalmente, a experiência brasileira apresenta uma solução original para a alternativa proposta por Paul Romer em um ensaio sobre o conhecimento e a economia do desenvolvimento, de usar idéias inventadas em outros lugares ou produzir as próprias idéias de alguém ${ }^{22}$. Romer compara dois modelos que se contrastam: o da ilha Maurício, que usa idéias estrangeira estimulando investimentos externos, e o de Taiwan, que incentiva a produção interna de conhecimento, aumentando seus investimentos em R\&D. Os laboratórios brasileiros de genéricos ilustram um outro modelo, que consiste em usar invenções estrangeiras por meio de engenharia reversa e a produção local de inovações derivadas direta ou indiretamente de copiar: diretamente, quando a cópia de medicamentos é acompanhada por adições e aperfeiçoamentos possíveis de serem patenteados e, indiretamente, quando os laboratórios de genéricos reutilizam conhecimento adquirido durante a fase de cópia para iniciar novos projetos de pesquisa. Dois dos cinco laboratórios farmacêuticos que estudamos desenvolveram essa trajetória de copia para pesquisa de novos medicamentos. Além da produção de conhecimentos implícita na cópia, esta leva também à criação ou ampliação de laboratórios de R\&D. Estes são fundamentalmente laboratórios analíticos - para caracterizar e controlar matérias-primas - e laboratórios de sínteses e fórmulas. Além disso, a produção de medicamentos genéricos para o programa contra a Aids revitalizou a reflexão e as iniciativas voltadas para a reformulação da indústria farmacoquímica no Brasil pelo governo, pela indústria privada e pelas universidades ${ }^{23}$.

\section{Notas}

1. Esse projeto de lei altera o artigo 18 da lei de patentes brasileira sobre exclusões da patenteabilidade. O que se segue não é patenteável: “... o medicamento assim como seu respectivo processo de obtenção, específico para a prevenção e o tratamento da Aids". Lei No 22/03, junho de 2005.

2. Entrevista com C. Possas, do Programa Brasileiro de Aids, em setembro de 2005.

3. Houve três crises relacionadas às licenças compulsórias para ARVs: em agosto de 2001, setembro de 2003 e junho de 2005. Nas três ocasiões, o Ministério da Saúde ameaçou usar uma licença compulsória, mas finalmente voltou atrás quando conseguiu um acordo sobre os preços dos ARVs comprados de laboratórios internacionais que lideram o mercado.

4. Essa exclusão foi discutida no projeto de lei aprovado pela Câmara dos Deputados em junho de 2005.

5. Sobre essa questão, o leitor poderá encontrar mais informações no trabalho da British Commission on Intellectual Property Rights intitulado "Integrating Intellectual Property Rights and Development Policy”, Londres, setembro de 2002.

6. Cf. o trabalho, de Jane Lajouwe, sobre a indústria farmacêutica indiana intitulado "The introduction of pharmaceutical patents in India: Heartless Exploitation of the Poor and Suffering?", NBER Working Paper $\mathrm{N}^{\circ}$ 6366, janeiro de 1998.

7. Decreto 9.313, de 13 de novembro de 1996. Lembremos que o acesso universal aos serviços de saúde é um direito constitucional no Brasil (Artigo 196 da Constituição de 1988).

8. O Brasil tem 18 laboratórios estatais. Seis estão envolvidos na produção de ARVs para o programa contra a Aids.

9. Entre 1996 e 2001, a produção de laboratórios públicos resultou em uma queda, em média, de $71 \%$ nos preços, em comparação aos preços de moléculas compradas de laboratórios internacionais.

10. Esse tipo de troca de tecnologia e cooperação no campo dos ARVs concretiza uma recomendação feita num relatório do Banco Mundial sobre o setor farmacêutico no Brasil intitulado "Public Policies in the Pharmaceutical Sector: A Case Study of Brazil", Jillian Clare Cohen, janeiro de 2000, 25 páginas.

11. No entanto, os investimentos de laboratórios brasileiros privados eram insuficientes para atingir esse objetivo. Em 1988, laboratórios estrangeiros controlavam 2/3 do mercado.

12. Ambos são ligados pelo comércio, uma vez que os laboratórios indianos fornecem matérias-primas para os laboratórios brasileiros.

13. Relatório da Comissão sobre Direitos de Propriedade Intelectual intitulado "Integrando Direitos de Propriedade Intelectual e Política de Desenvolvimento”. GlaxoSmithKline, novembro de 2002, 15 páginas.

14. Realizamos 45 entrevistas em 2002, 2003 e 2004. 
Visitamos os laboratórios de R\&D e instalações industriais desses diferentes laboratórios farmacêuticos. Essa pesquisa foi financiada pela ANRS (Agence française de recherche sur le sida), a agência nacional francesa de pesquisa sobre Aids.

15. Cassier, M. e Correa, M. 2003. Patents, innovation and Public Health: Brazilian Public-Sector Laboratories' Experience in Cpying AIDS Drugs. In Economics of Aids Aid and Access in Developing Countries. Ed. ANRS, p. 89-107; Cassier, M. e Correa, M. 2004. Patenting Drugs? An anthropological vision of property. $4 \mathrm{~S}$ and EASST Conference, Public Proofs, Science, Technology and Democracy, agosto de 2004, Ecole des Mines, Paris; Cassier, M. e Correa, M. 2005. La copie des antiretroviraux dans les laboratories publics et privés brésiliens, Montreal, Congresso Internacional sobre Medicamentos, $30 \mathrm{de}$ agosto a 2 de setembro.

16. O número de patentes registradas por universidades brasileiras aumentou sibstancialmente a partir de 1997.

17. O laboratório estatal teria produzido uma versão genérica do Kaletra por 68 centavos de dólar para substituir o Kaletra, do Abbott, cujo custo era de US\$ 1,17.

18. O projeto de lei introduz uma emenda ao Artigo 18 da Lei de Patentes brasileira que trata das exclusões da patenteabilidade. Nos termos dessa lei, o que se segue não é patenteável: “... o medicamento assim como seu respectivo processo de obtenção, específico para a prevenção e o tratamento da Aids". Lei No 22/03, junho de 2005. Em seguida, este projeto de lei ainda teve de ser aprovado pelo Senado e sancionado pelo presidente da República.

19. Essa situação tem uma longa história no campo farmacêutico. Por exemplo, no início do século, pesquisadores do laboratório francês Poulenc beneficiaram-se do status não-patenteável de medicamentos na França para copiarem sistematicamente patentes farmacêuticas alemãs. Cf. Cassier. 2004. Brevets pharmaceutiques et santé publique en France: opposition et dispositifs spécifiques d'appropriation des médicaments entre 1791 et 2004. Entreprises et Histoire $\mathrm{n}^{\circ} 36$. Ver também o exemplo da química e medicamentos na Suíça no século XIX e início do século XX. Macleod, C. The patent controversy in the $19^{\text {th }}$ century. Congresso "History and Economics of Intellectual Property", 3-4 de junho de 2005, Paris.

20. Implementation of the Doha Declaration on TRIPS and public health, 28 de agosto de 2003, Organização Mundial do Comércio.

21. O conflito sobre licenças compulsórias para o Efavirenz e o Nelfinavir, em setembro de 2003, foi precedido pela ida de uma delegação de químicos brasileiros à Índia e à China.

22. Romer, P. Two strategies for economic development: using ideas and producing ideas. Seminários do Congresso Anual sobre Desenvolvimento Econômico organizado pelo do Banco Mundial, 1992.

${ }^{23}$ Em 2003, diversos seminários foram realizados no Brasil sobre os assuntos "Projetos de inovação relacionados à saúde" (Fundação Oswaldo Cruz, 9-10 de junho de 2003) e "O complexo industrial da saúde" (BNDES, Ministério do Desenvolvimento, Indústria e Comércio Exterior, 5-7 de maio de 2003). Em 2005 e 2006, a Academia de Ciências organizou um ciclo de conferências sobre política farmacêutica e inovação. Ver também o relatório, de Antunes e Fortunak, intitulado $A$ produção de ARVs no Brasil. 2006.

\section{Referências bibliográficas}

ANTUNES O.; FORTUNAK J.M.: Arvs production in Brazil: an evaluation. Report for the Brazilian Interdisciplinary Aids Association (ABIA) and MSF Brazil, 2006, 8 p.

CASSIER, M.; CORREA, M. Patents, innovation and Public Health: Brazilian Public-Sector Laboratories Experience in Copying AIDS Drugs'. In: Economics of Aids Aid and Access in Developing Countries, Ed. ANRS, 2003, p.89-107.

CASSIER, M. Brevets pharmaceutiques et santé publique en France entre 1791 et 2004: opposition et dispositions spécifiques d'appropriation des médicaments, revue Entreprises et Histoire, 2004, p.29-47.

COHEN J.C, Public policies in the pharmaceutical sector: a case study of Brazil, January, World Bank, 2000, 25 p.

COMMISSION ON INTELLECTUAL PROPERTY RIGHTS (CIPR), Integrating Property Rights and Development Policy, s.d. 178 p.

GLAXOWELLCOME, Commission on Intellectual Property Rights Report on Integrating Intellectual Property Rights\&Development Policy: comments from GlaxoSmithKline, November, 2002, 15 p.

LANJOUWE, J, The introduction of Pharmaceutical Products Patents in India : Heartless exploitation of the poor and suffering? s.l. Economic Growth Center, Yale University, 1997, 54 p.

MACLEOD, “"The patent controversy in the $19^{\text {th }}$ century", conference on 'History and Economics of Intellectual Property Rights', 3-4 June 2005, Paris.

ROMER P, Two strategies for Economic Development: Using Ideas and Producing Ideas, Proceedings of the World Bank Annual Conference on Development Economics. The World Bank, p. 63-91. 


\section{Sobre os autores}

\section{Maurice Cassier}

Sociólogo e diretor de pesquisas do CNRS (Centro Nacional de Pesquisa Científica). O foco de seu trabalho é no conhecimento em propriedade intelectual, técnicas e produtos nos campos da ciência, formas de vida e saúde, nos séculos 19 e 20. Suas mais recentes publicações tratam da apropriação das vacinas de Louis Pasteur, contestação às patentes de genes do câncer de mama na Europa, e engenharia reversa nos laboratórios de genéricos brasileiros.

\section{Marilena Correa}

Psiquiatra especializada em saúde pública, mestre em Medicina Social e doutora em Ciências Sociais e da Saúde. Atualmente é pesquisadora convidada do Centre de Recherches Medecine, Sciences Santé et Societe - CNRS, L'École des hautes études en sciences sociales, e professora do Instituto de Medicina Social da Universidade Estadual do Rio de Janeiro. Seu atual campo de pesquisa é em inovação biomédica. Já publicou livros, capítulos de livros e artigos sobre reprodução humana e procriação medicamente assistida, biotecnologia, bioética e ética em pesquisa biomédica. Foi membro dos Comitês de Ética em Pesquisa da Fundação Oswaldo Cruz (1999 até 2006) e da Universidade do Estado do Rio de Janeiro onde foi coordenadora. 